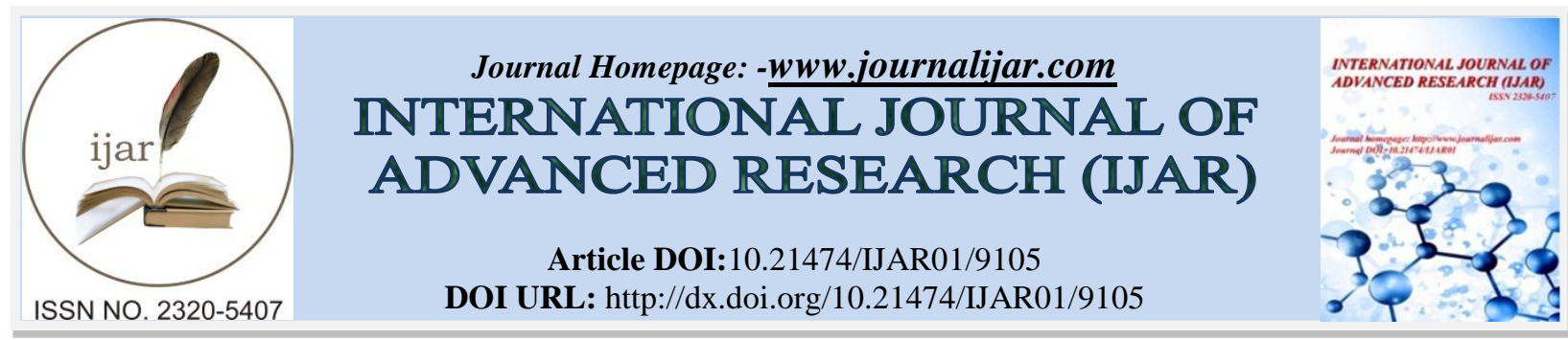

RESEARCH ARTICLE

\title{
DEVELOPMENT AND OPTIMIZATION OF BI LAYERED FLOATING TABLET OF SUCRALFATE AND METOPROLOL SUCCINATE.
}

Sreedhar Ranjan Das, Dr.Bibhuti Bhusan Panigrahi And Dr.ManojKumar Pani.

PG Department of Pharmaceutics, Indira Gandhi Institute of Pharmaceutical Sciences, Bhubaneswar.

\section{Manuscript Info}

\section{Manuscript History}

Received: 20 March 2019

Final Accepted: 22 April 2019

Published: May 2019

Key words:-

Optimization. Sucralfate, Metoprolol

Succinate, Bi-layered Floating Tablet.

\begin{abstract}
Objective: To optimize and develop Bi layered floating tablet (SFMS) containing ulcer protective Sucralfate as immediate release layer and anti hypertensive Metoprolol Succinate as sustained release layer.

Method: 15 formulations of Sucralfate and 10 formulations of Metoprolol Succinate is taken. By changing the concentration of Superdisintigrant, Surfectants, Alkalizing agents \& Binding agents of Sucralfate and changing concentrations of Alkalizing agents and Polymers of Metoprolol Succinate the OSFMS (Optimized Sucralfate and Metoprolol Succinate Formulation) is generated.. Result: Within 5 minutes in acidic medium, 7\% Superdisintigant (Crosspovidone), $7 \%$ Surfectant (Polysorbate-80), $15 \%$ Alkalizing agents(Sodium bicarbonate), 5\% HPC (Binding agent) averagely produce $68.56 \%$ drug release. Within 20 hours in acidic medium , 30\% Alkalizing agents(Sodium bicarbonate) , 50\% Soluablepolymer (HPMC K) ,40\% Polymer (Udragid RSPO, 35\% HPC Polymer(NaCMC), 30\% Polymer (Sodiumalginate) ,25\% Polymer (HPC), 20\% Polymer, Udragid RS), 5\% HPC Polymer (PVPK) produce averagely $100.06 \%$ drug release. Conclusion:The optimized formulation $400 \mathrm{mg}$ tablet weight of OSFMS (Optimized Sucralfate and Metoprolol Succinate Formulation) produce better result and identified as better formulation for further studies.
\end{abstract}

Copy Right, IJAR, 2019,. All rights reserved.

\section{Introduction:-}

The term Optimization ${ }^{1}$ is defined as to make perfect, effective ,or functional as possible .It is the process of finding the best way of using the existing resources while taking into the account of all factors. that influences decision in any experiments. The Morden Pharmaceutical optimization involves systematic Design of Experiment (DOE) .to improve formulation irregularities.

Bilayer floating drug delivery system is combined principle of Bi -Layered Tablet as well as floating mechanism ${ }^{2}$ Drug absorption from G.I.T depends upon contact time with intestinal mucosa ${ }^{-3} \mathrm{Bi}$-layered Tablet materials involve both the compressibility and consolidation ${ }^{4} \mathrm{Bi}$-Layered tablet contain immediate and sustained release layer ${ }^{5}$ The incorporated drug remain in gastric region for several hours and produce prolong gastric resistance time and improve bioavailability .It reduce drug waste and enhance the solubility of drug ${ }^{6}$. The drug release slowly at desired rate and increase GRT and better control of fluctuations in plasma drug concentration. ${ }^{7}$

Corresponding Author:-Sreedhar Ranjan Das.

Address:-PG Department of Pharmaceutics, Indira Gandhi Institute of Pharmaceutical Sciences, 
Both Sucralfate and Metoprolol succinate produce minor drug interaction in pregnancy and lactate mother ${ }^{8}$ Both the drugs are administrated in empty stomach in presence of acid medium? ${ }^{9}$. They act at stomach as well as at upper part of small intestine and produce better bioavilability ${ }^{10}$

The present study is to develop and to optimize ${ }^{11}$ Bi-Layered Floating Tablet of Sucralfate and Metoprol succinate to formulate a new formulation producing better release at low dose. and to make a comparison study between the initial formulation and optimized formulation.

\section{Materials and methods:-}

15 formulations of Sucralfate and 10 formulations of Metoprol Succinate are taken.. ${ }^{\mathbf{1 2}}$

Table 1:-List of excipients used for the preparation of Sucralfate layer (SF1---SF9)

\begin{tabular}{|c|c|c|c|c|c|c|c|c|c|c|}
\hline & \multirow[t]{2}{*}{ INGREDIENTS } & \multicolumn{9}{|c|}{ QUANTITY PER TABLET IN MG } \\
\hline & & SF 1 & SF 2 & SF 3 & SF 4 & SF 5 & SF 6 & SF 7 & SF 8 & SF 9 \\
\hline 1 & Sucralfate & 100 & 100 & 100 & 100 & 100 & 100 & 100 & 100 & 100 \\
\hline 2 & Crospovidone & 0 & 6.25 & 6.25 & 6.25 & 6.25 & 6.25 & 6.25 & 6.25 & 6.25 \\
\hline 3 & Calcium carbonate & 23 & 25 & 25 & 25 & 0 & 25 & 0 & 0 & 0 \\
\hline 4 & Aerosil & 1 & 1 & 1 & 1 & 1 & 1 & 1 & 1 & 1 \\
\hline 5 & Lactose MHF & 31.25 & 31.25 & 31.25 & 31.25 & 31.25 & 31.25 & 31.25 & 31.25 & 31.25 \\
\hline 6 & MCC PH 101 & 48.45 & 45.2 & 44.575 & 44.575 & 74.575 & 49.575 & 49.575 & 49.825 & 46.075 \\
\hline 7 & Magnesium Stearate & 0.5 & 0.5 & 0.5 & 0.5 & 0.5 & 0.5 & 0.5 & 0.5 & 0.5 \\
\hline 8 & Sodium bicarbonate & 5 & 5 & 5 & 5 & 0 & 0 & 25 & 25 & 25 \\
\hline 9 & Polysorbate 80 & 0 & 0 & 0 & 0.625 & 0.625 & 0.625 & 0.625 & 0.375 & 0.375 \\
\hline 10 & SLS & 0 & 0 & 0.625 & 0 & 0 & 0 & 0 & 0 & 0 \\
\hline 11 & Sunset yellow & 0.312 & 0.3125 & 0.3125 & 0.3125 & 0.3125 & 0.3125 & 0.3125 & 0.3125 & 0.3125 \\
\hline 12 & \begin{tabular}{|l} 
Purified Water \\
\end{tabular} & q.s & q.s & q.s & q.s & q.s & q.s & q.s & q.s & q.s \\
\hline & \multicolumn{2}{|c|}{ Tablet wt in $(\mathrm{mg})$} & 214.5 & 214.5 & 214.5 & 214.5 & 214.5 & 214.5 & 214.5 & 214.5 \\
\hline
\end{tabular}

Table 2:-List of excipients used for the preparation of Sucralfate layer (SF10---SF15)

\begin{tabular}{|c|l|c|c|c|c|c|c|}
\hline S1 & INGREDIENTS & \multicolumn{7}{|c|}{ QUANTITY PER TABLET IN MG } \\
\hline No & & SF 10 & SF 11 & SF12 & SF 13 & SF 14 & SF 15 \\
\hline 1 & Sucralfate & 100 & 100 & 100 & 100 & 100 & 100 \\
\hline 2 & Crospovidone & 6.25 & 6.25 & 3.75 & 8.75 & 6.25 & 6.25 \\
\hline 3 & Aerosil & 1 & 1 & 1 & 1 & 1 & 1 \\
\hline 4 & Lactose MFL & 31.25 & 31.25 & 31.25 & 31.25 & 31.25 & 31.25 \\
\hline 5 & MCC PH101 & 48.575 & 43.575 & 48.575 & 43.575 & 52.325 & 39.825 \\
\hline 6 & Magnesium Stearate & 0.5 & 0.5 & 0.5 & 0.5 & 0.5 & 0.5 \\
\hline 7 & Sodium Bicarbonate & 25 & 25 & 25 & 25 & 18.75 & 31.25 \\
\hline 8 & Polysorbate 80 & 0.375 & 0.375 & 0.375 & 0.375 & 0.375 & 0.375 \\
\hline 9 & HPC-L & 1.25 & 6.25 & 3.75 & 3.75 & 3.75 & 3.75 \\
\hline 10 & Sunset Yellow & 0.3125 & 0.3125 & 0.3125 & 0.3125 & 0.3125 & 0.3125 \\
\hline 11 & Purified Water & q.s & q.s & q.s & q.s & q.s & q.s \\
\hline & Total Weight & 214.5 & 214.5 & 214.5 & 214.5 & 214.5 & 214.5 \\
\hline
\end{tabular}


Table 3:-List of excipients used for the preparation of Metoprolol Succinate sustained release layer .

\begin{tabular}{|c|c|c|c|c|c|c|c|c|c|c|c|}
\hline \multirow{2}{*}{$\begin{array}{l}\text { SL. } \\
\text { NO }\end{array}$} & \multirow[t]{2}{*}{ INGREDIENTS } & \multicolumn{10}{|c|}{ QUANTITY PER TABLET IN MG } \\
\hline & & $\begin{array}{c}\mathrm{MSF} \\
1\end{array}$ & $\begin{array}{c}\text { MSF } \\
2\end{array}$ & $\begin{array}{c}\text { MSF } \\
3\end{array}$ & $\begin{array}{c}\text { MSF } \\
4\end{array}$ & $\begin{array}{c}\text { MSF } \\
5\end{array}$ & $\begin{array}{c}\text { MSF } \\
6\end{array}$ & $\begin{array}{c}\text { MSF } \\
7\end{array}$ & $\begin{array}{c}\text { MSF } \\
8\end{array}$ & $\begin{array}{c}\text { MSF } \\
9\end{array}$ & $\begin{array}{c}\text { MSF1 } \\
0\end{array}$ \\
\hline 1 & Metoprolol Succinate & 50 & 50 & 50 & 50 & 50 & 50 & 50 & 50 & 50 & 50 \\
\hline 2 & HPMC K 100M & 100 & 100 & 100 & 100 & 100 & 100 & 100 & 100 & 100 & 75 \\
\hline 3 & $\begin{array}{l}\text { SODIUM } \\
\text { BICARBONATE }\end{array}$ & 75 & 100 & 100 & 100 & 100 & 100 & 100 & 100 & 100 & 100 \\
\hline 4 & AEROSIL & 3 & 3 & 3 & 3 & 3 & 3 & 3 & 3 & 3 & 3 \\
\hline 6 & EUDRAGIT RSPO & 30 & 30 & - & & - & - & - & - & - & 30 \\
\hline 7 & EUDRAGIT RLPO & - & - & 30 & & - & - & - & - & - & - \\
\hline 8 & EUDRAGIT RS100 & - & - & & 30 & - & - & - & - & - & - \\
\hline 8 & $\mathrm{Na} \mathrm{CMC}$ & - & - & - & - & 30 & - & - & - & - & - \\
\hline 9 & SODIUM ALGINATE & - & - & - & - & & 30 & - & - & - & - \\
\hline 10 & HPC KLUCEL HF & - & - & - & - & - & - & 30 & - & - & - \\
\hline 11 & PVPK 90 & - & - & - & - & - & - & - & 30 & - & \\
\hline 12 & ETHYL CELLULOSE & - & - & - & - & - & - & - & - & 30 & - \\
\hline 13 & TALC & 3 & 3 & 3 & 3 & 3 & 3 & 3 & 3 & 3 & 3 \\
\hline 14 & IPA & Q.S & Q.S & Q.S & Q.S & Q.S & Q.S & Q.S & Q.S & Q.S & Q.S \\
\hline 15 & PURIFIED WATER & Q.S & Q.S & Q.S & Q.S & Q.S & Q.S & Q.S & Q.S & Q.S & Q.S \\
\hline
\end{tabular}

Optimization of Sucralfate formulation.

In vitro drug release study of Sucralfate tablets by changing concentration of different formulations.

These in-vitro drug release studies of Sucralfate tablets were carried out as per USP guidelines. The dissolution method and equipment were validated before the study. The dissolution of all batches of tablets was carried out using LABINDIA DISSO 2000 with automatic sampler, a USP Apparatus-II Paddle type apparatus with $0.1 \mathrm{~N} \mathrm{HCl}$ (and $6.8 \mathrm{pH}$ phosphate buffer respectively) as dissolution media with volume of $900 \mathrm{ml}$. The dissolution medium was subjected to degassing by placing the dissolution vessel with medium in a water bath at $37 \pm 2^{\circ} \mathrm{C}$. The paddle speed was set at $75 \mathrm{rpm}$ and the temperature was maintained at $37 \pm 0.5^{\circ} \mathrm{C}$. The sampling volume was $10 \mathrm{ml}$ with a rinsing volume of $3 \mathrm{ml}$ and with $10 \mathrm{ml}$ replacing volume. The sampling intervals were 5, 10, 15, 20, 30 and 45minutes. The collected samples were analyzed as pooled samples at $281 \mathrm{~nm}$ using UV-Spectrophotometer

In-vitro drug dissolution data of Sucralfate Tablet with or without (Super disintegrants - Crosspovidone) in presence of $0.1 \mathrm{HCL}$ and 6.8 Phosphate buffer are studied. [SF1 (Nill),SF2 (1\%),SF9(3\%),SF12(5\%),SF13(7\%)]

Table 4:-Cumulative drug dissolution data of Sucralfate Tablets formulated with and without (Superdisintegrant Crosspovidone) [ SF1 (Nill),SF2 (1\%)]

\begin{tabular}{|c|c|c|c|c|}
\hline \multirow{2}{*}{ Time (min) } & \multicolumn{4}{|c|}{ Cumulative \% drug release } \\
\cline { 2 - 5 } & \multicolumn{2}{|c|}{$0.1 \mathrm{~N}$ HCL } & \multicolumn{2}{c|}{$6.8 \mathrm{pH}$ phosphate buffer } \\
\cline { 2 - 5 } & SF1(Nill) & SF2(1\%) & SF1(Nill) & SF2(1\%) \\
\hline 0 & 0 & 0 & 0.000 & 0.000 \\
\hline 5 & 3.974 & 26.169 & 4.891 & 53.011 \\
\hline
\end{tabular}




\begin{tabular}{|c|c|c|c|c|}
\hline 10 & 5.976 & 43.395 & 10.796 & 71.969 \\
\hline 15 & 13.964 & 77.174 & 26.306 & 83.625 \\
\hline 20 & 32.618 & 79.845 & 56.797 & 100.289 \\
\hline 30 & 48.731 & 81.843 & 70.387 & - \\
\hline 45 & 50.824 & 95.191 & 75.755 & - \\
\hline $\mathrm{R}$ & 0.9489 & 0.9706 & 0.9608 & 0.9963 \\
\hline $\mathrm{k}(\min -1)$ & 0.017 & 0.0664 & 0.0333 & 0.3022 \\
\hline $\mathrm{T}_{50}(\min )$ & 40.7 & 10.4 & 20.7 & 2.3 \\
\hline $\mathrm{T}_{90}(\mathrm{~min})$ & 135.2 & 34.7 & 68.8 & 7.6 \\
\hline
\end{tabular}

Table 5:-Cumulative drug dissolution data observed from Sucralfate Tablets formulated with different concentrations of (Superdisintegrant - Crosspovidone) present in the concerned formulation.[ SF9(3\%),SF12(5\%),SF13(7\%)]

Nill - Without Superdisintigrants. \% - Quantity of Superdisintigrant

\begin{tabular}{|c|c|c|c|c|c|c|}
\hline \multirow{2}{*}{ Time (min) } & \multicolumn{7}{|c|}{ Cumulative \% drug release } \\
\cline { 2 - 7 } & \multicolumn{7}{|c|}{$0.1 \mathrm{~N} \mathrm{HCL}$} & \multicolumn{3}{c|}{ 6.8pH phosphate buffer } \\
\cline { 2 - 7 } & SF9(3\%) & SF12(5\%) & SF13(7\%) & SF9(3\%) & SF12(5\%) & SF13(7\%) \\
\hline 0 & 0 & 0 & 0.00 & 0 & 0 & 0 \\
\hline 5 & 56.98 & 63.689 & 91.42 & 74.3 & 40.9 & 80.1 \\
\hline 10 & 81.83 & 70.08 & 90.05 & 99.4 & 90.2 & 101.7 \\
\hline 15 & 89.08 & 86.864 & 95.50 & 100.5 & 95.7 & - \\
\hline 20 & 94.03 & 91.045 & 102.14 & - & 97.9 & - \\
\hline 30 & 98.37 & 101.602 & - & - & 101 & - \\
\hline 45 & 101.41 & 98.727 & - & - & - & - \\
\hline R & 0.9965 & 0.9826 & 0.9951 & 0.9482 & 0.9874 & 0.999 \\
\hline k (min-1) & 0.1954 & 0.1813 & 0.2822 & 0.428 & 0.2088 & 0.6032 \\
\hline T50 & 4.3 & 3.8 & 2.5 & 1.6 & 3.3 & 1.1 \\
\hline T90 & 14.4 & 12.7 & 8.2 & 5.4 & 11 & 3.8 \\
\hline
\end{tabular}

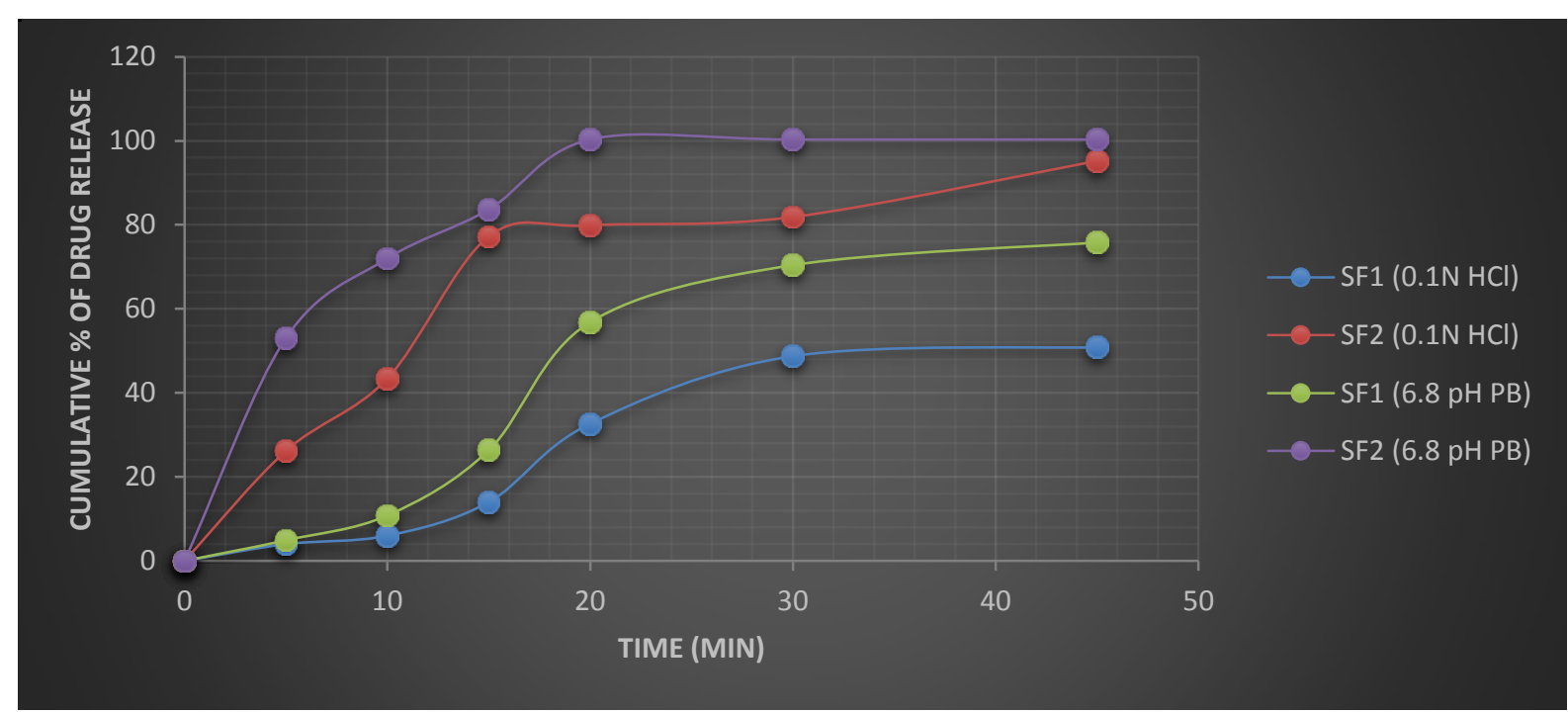

SF1: Without Superdisintegrant; SF2: With super disintegrant(1\%)

Fig 1:-In vitro drug dissolution profiles of Sucralfate Tablets formulated with and without different (Superdisintegrant - Crosspovidone) at $0.1 \mathrm{~N} \mathrm{HCL}$ and $6.8 \mathrm{pH}$ respectively. 


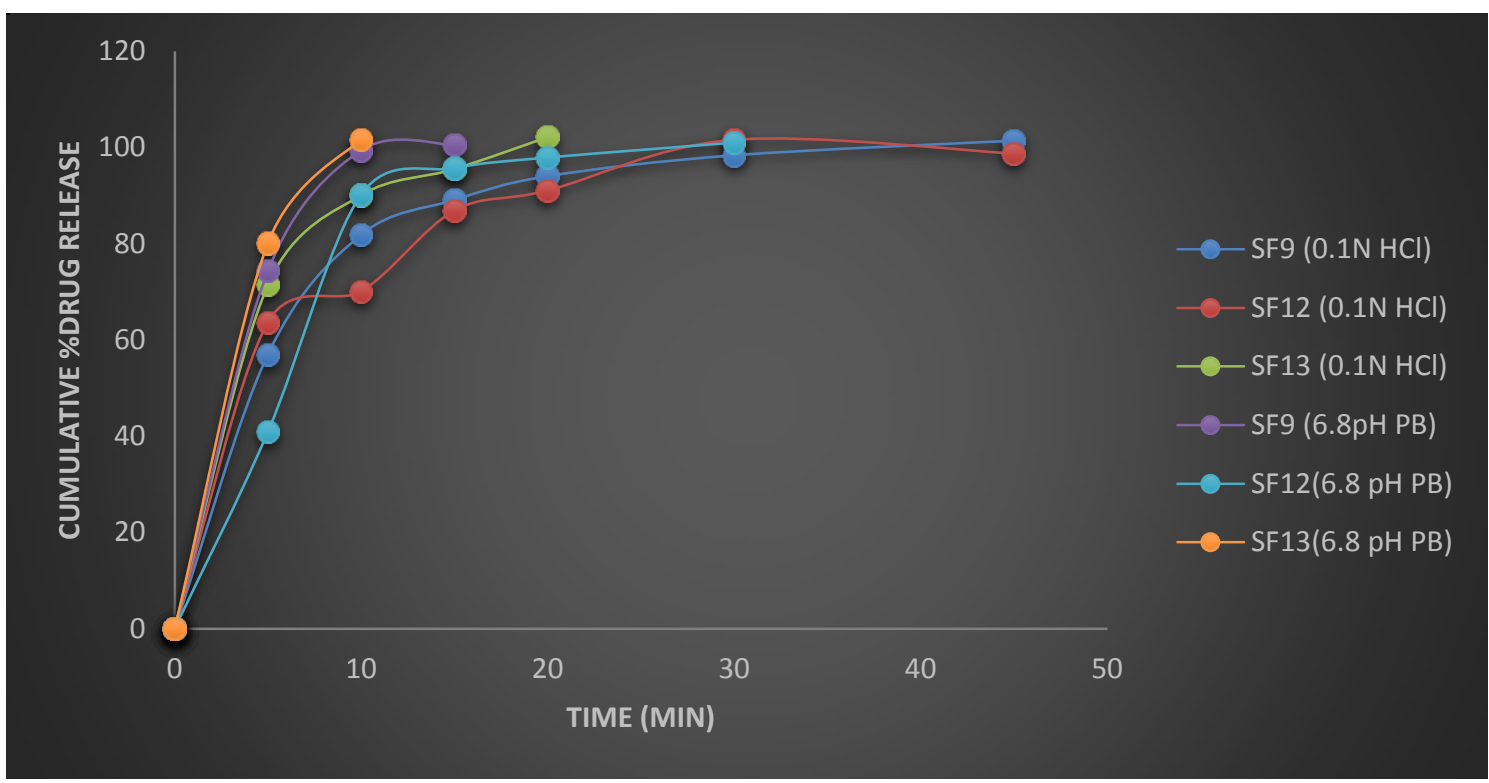

SF9: 3\% super disintegrant; SF12: 5\% superdisintegrant; SF13: 7\% superdisintegrant

Fig 2:-In vitro drug dissolution profiles of Sucralfate tablets formulated with different concentrations of (Superdisintegrant - Crosspovidone) at $0.1 \mathrm{~N} \mathrm{HCL}$ and $6.8 \mathrm{pH}$ respectively.

Drug dissolution data of with different (Surfectants ;SLS and Polysobate -80 )in presence of 0.1 HCL \& 6.8 Phosphate buffer is done [SF2(Nill),SF3(SLS),SF4(P-80 0.7\%), SF7(P-80 0.5\%), SF8 (P-80 0.3\%)]

Table 6:-Cumulative drug dissolution data of Sucralfate Tablets formulated with different (Surfactants :SLS and Polysorbate-80 ) [SF2(Nill),SF3(SLS),SF4(P-80 0.7\%), ]

\begin{tabular}{|c|c|c|c|c|c|c|}
\hline \multirow[t]{3}{*}{ Time (min) } & \multicolumn{6}{|c|}{ Cumulative $\%$ drug release } \\
\hline & \multicolumn{3}{|c|}{$0.1 \mathrm{~N} \mathrm{HCL}$} & \multicolumn{3}{|c|}{$6.8 \mathrm{pH}$ phosphate buffer } \\
\hline & $\begin{array}{c}\text { SF2 } \\
\text { (Nill) }\end{array}$ & $\begin{array}{c}\text { SF3 } \\
(5 \% \text { SLS })\end{array}$ & $\begin{array}{c}\text { SF4 } \\
(7 \% \text { P_80) }\end{array}$ & $\begin{array}{c}\text { SF2 } \\
\text { (Nill) }\end{array}$ & $\begin{array}{c}\text { SF3 } \\
(5 \% \text { SLS })\end{array}$ & $\begin{array}{c}\text { SF4 } \\
(0.7 \% \\
\text { P-80) }\end{array}$ \\
\hline 0 & 0 & 0 & 0 & 0.000 & 0.00 & 0.00 \\
\hline 5 & 26.169 & 5.721 & 96.74 & 53.011 & 3.68 & 55.64 \\
\hline 10 & 43.395 & 36.026 & 77.33 & 71.969 & 25.24 & 81.80 \\
\hline 15 & 77.174 & 47.145 & 93.94 & 83.625 & 54.53 & 99.53 \\
\hline 20 & 79.845 & 58.776 & 101.55 & 100.289 & 63.62 & 101.08 \\
\hline 30 & 81.843 & 71.529 & - & - & 86.22 & - \\
\hline 45 & 95.191 & 79.309 & - & - & 97.93 & - \\
\hline $\mathrm{R}$ & 0.9706 & 0.9827 & 0.9813 & 0.9963 & 0.9783 & 0.9261 \\
\hline $\mathrm{k}(\min -1)$ & 0.0664 & 0.0397 & 0.2723 & 0.3022 & 0.0705 & 0.2501 \\
\hline T50 & 10.4 & 18.3 & 2.5 & 2.3 & 9.8 & 2.8 \\
\hline T90 & 34.7 & 16.8 & 8.5 & 7.6 & 37.7 & 9.2 \\
\hline
\end{tabular}

Table7:-Cumulative drug dissolution data of Sucralfate Tablets formulated with different concentrations of (Surfactants :SLS and Polysorbate-80) [SF7(P-80 0.5\%), SF8 (P-80 0.3\%)]

\begin{tabular}{|c|c|c|c|c|}
\hline \multirow{2}{*}{ Time (min) } & \multicolumn{3}{|c|}{ Cumulative \% drug release } \\
\cline { 2 - 5 } & \multicolumn{3}{|c|}{$0.1 \mathrm{~N} \mathrm{HCL}$} & \multicolumn{2}{c|}{$6.8 \mathrm{pH}$ phosphate buffer } \\
\cline { 2 - 5 } & $\begin{array}{c}\text { SF7 } \\
(5 \% \mathrm{P}-80)\end{array}$ & $\begin{array}{c}\text { SF8 } \\
(3 \% \mathrm{P}-80)\end{array}$ & $\begin{array}{c}\text { SF7 } \\
(5 \% \mathrm{P}-80)\end{array}$ & $\begin{array}{c}\text { SF8 } \\
(3 \% \mathrm{P}-80)\end{array}$ \\
\hline
\end{tabular}




\begin{tabular}{|c|c|c|c|c|}
\hline 0 & 0 & 0 & 0 & 0 \\
\hline 5 & 64 & 48.99 & 58.4 & 55.5 \\
\hline 10 & 71.7 & 75.18 & 95.1 & 93.5 \\
\hline 15 & 82.8 & 84.62 & 100.6 & 99.3 \\
\hline 20 & 86.9 & 88.41 & - & - \\
\hline 30 & 100.6 & 100.35 & - & 0.935 \\
\hline 45 & - & - & - & 0.2173 \\
\hline $\mathrm{R}$ & 0.9639 & 0.9868 & 0.9706 & 3.2 \\
\hline $\mathrm{k}(\mathrm{min}-1)$ & 0.1744 & 0.173 & 0.3801 & 10.6 \\
\hline $\mathrm{T}_{50}(\min )$ & 4 & 4 & 1.8 & \\
\hline $\mathrm{T}_{90}(\min )$ & 13.2 & 13.3 & 6.1 & \\
\hline
\end{tabular}

Nill - Without Surfactants. \% - Quantity of Surfactants present in the concerned formulation.

SF2: Without surfactant; SF3: With SLS; SF4: With polysorbate80 ( $0.7 \%)$

Fig 3:-In vitro drug dissolution profiles of Sucralfate tablets formulated with different (Surfactants :SLS and

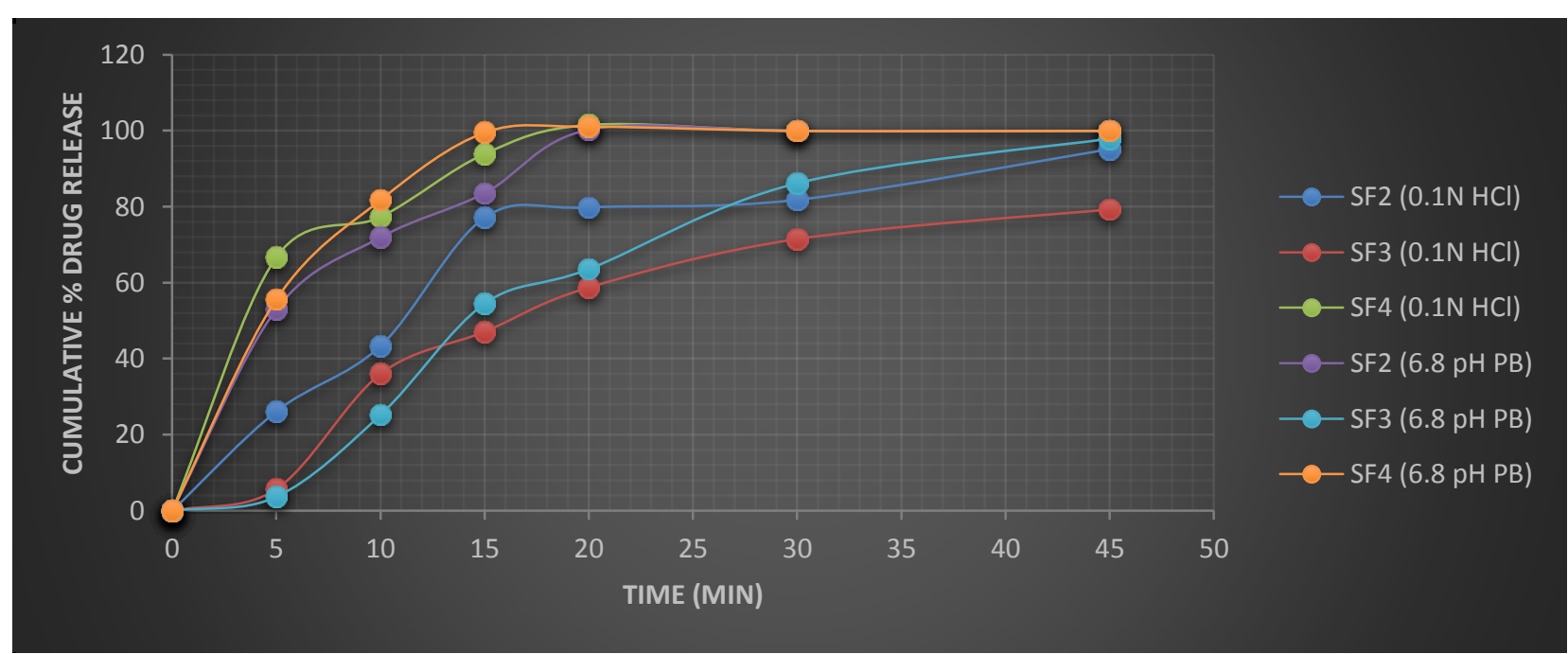

Polysorbate-80 ) at $0.1 \mathrm{~N} \mathrm{HCL}$ and $6.8 \mathrm{pH}$ respectively 


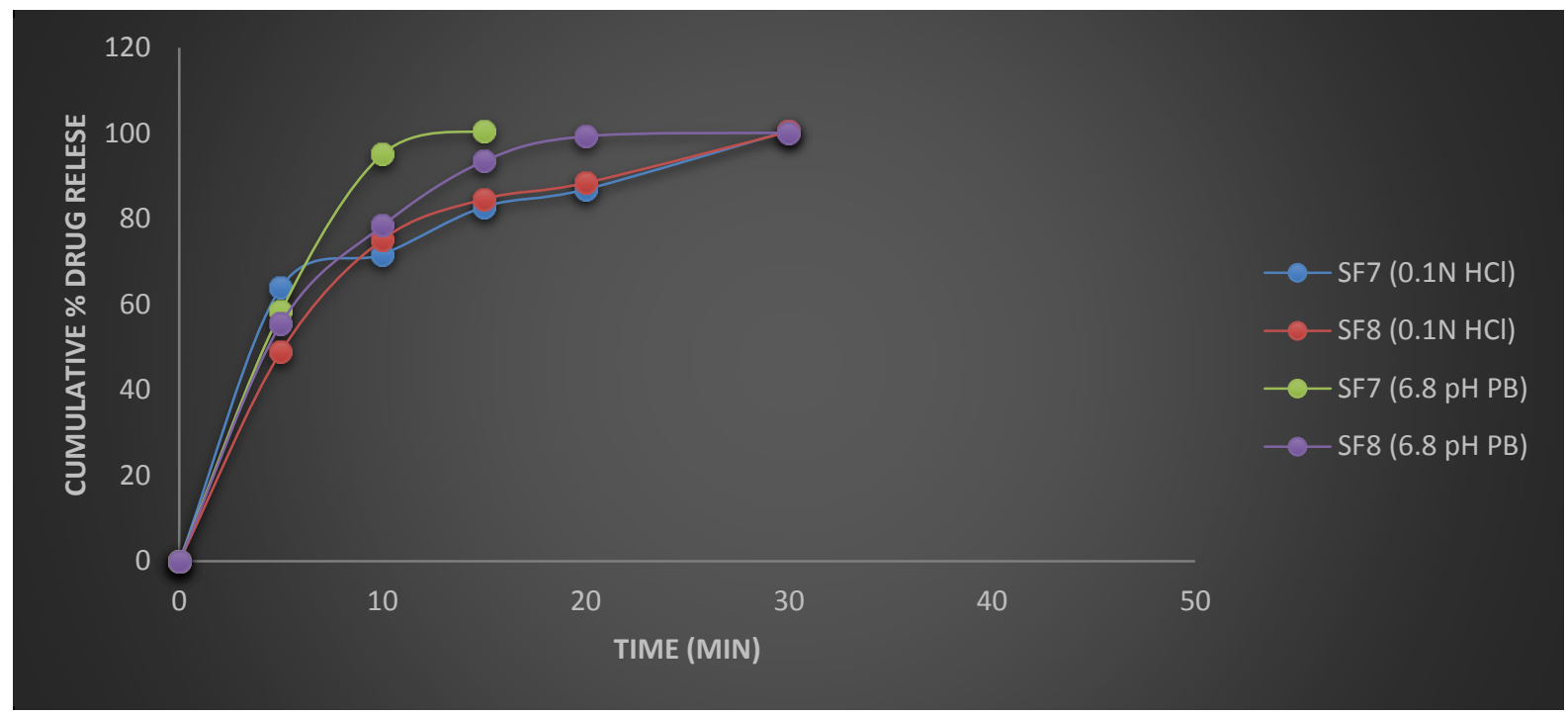

SF7: $0.5 \%$ poysorbate 80 ; SF8: $0.3 \%$ Polysorbate 80

Fig 4:-In vitro drug dissolution profiles of Sucralfate tablets formulated with different (Surfactants :SLS and Polysorbate-80 ) at $0.1 \mathrm{~N} \mathrm{HCL}$ and $6.8 \mathrm{pH}$ respectively.

Drug dissolution data of with different(Alkalizing agents ; $\mathbf{C a C O}_{3}$ and $\mathbf{N a H C O}_{3}$ ) in presence of $0.1 \mathrm{HCL}$ \& 6.8 Phosphate buffer is done [SF4-(Nill),SF5-30\% $\mathrm{CaCo}_{3}, \mathrm{SF} 6-25 \% ; \mathrm{CaCO}_{3}, \mathrm{SF} 7-20 \% \mathrm{CaCO}_{3}, \mathrm{SF} 9,-20 \% \mathrm{NaHCO}_{3}$, $\left.\mathrm{SF} 14-15 \% \mathrm{NaHCO}_{3} \mathrm{SF} 15-25 \% \mathrm{NaHCO}_{3}\right]$

Table 8:-Cumulative drug dissolution data of Sucralfate Tablets formulated with and without (Alkalizing agents : $\mathrm{CaCo}_{3}$ and ,NaHco3.) $\left[\mathrm{SF} 4-(\mathrm{Nill}), \mathrm{SF} 5-30 \% \mathrm{CaCo}_{3}\right]$

\begin{tabular}{|c|c|c|c|c|}
\hline \multirow[t]{3}{*}{ Time (min) } & \multicolumn{4}{|c|}{ Cumulative $\%$ drug release } \\
\hline & \multicolumn{2}{|c|}{$0.1 \mathrm{~N} \mathrm{HCL}$} & \multicolumn{2}{|c|}{$6.8 \mathrm{pH}$ phosphate buffer } \\
\hline & $\begin{array}{c}\text { SF4 } \\
\text { (Nill) }\end{array}$ & $\begin{array}{c}\text { SF5 } \\
30 \% \mathrm{CaCo}_{3}\end{array}$ & $\begin{array}{c}\text { SF4 } \\
\text { (Nill) }\end{array}$ & $\begin{array}{c}\text { SF5 } \\
30 \% \mathrm{CaCo}_{3}\end{array}$ \\
\hline 0 & 0 & 0 & 0.00 & 0 \\
\hline 5 & 66.74 & 11.43 & 55.64 & 3.5 \\
\hline 10 & 77.33 & 17.89 & 81.80 & 34.3 \\
\hline 15 & 93.94 & 24.03 & 99.53 & 71.6 \\
\hline 20 & 101.55 & 38.16 & 101.08 & 86.2 \\
\hline 30 & - & 49.82 & - & 100.1 \\
\hline 45 & - & 56.36 & - & - \\
\hline $\mathrm{R}$ & 0.9813 & 0.983 & 0.9261 & 0.9529 \\
\hline $\mathrm{k}(\min -1)$ & 0.2723 & 0.0201 & 0.2501 & 0.1583 \\
\hline $\mathrm{T}_{50}(\mathrm{~min})$ & 2.5 & 34.5 & 2.8 & 9.1 \\
\hline $\mathrm{T}_{90}(\min )$ & 8.5 & 114.6 & 9.2 & 29.6 \\
\hline
\end{tabular}

Table 9:-Cumulative drug dissolution data of Sucralfate Tablets formulated with different (Alkalizing agents: $\mathrm{CaCO}_{3}$ and ,NaHco3.) $\left[\mathrm{SF} 6-25 \% ; \mathrm{CaCO}_{3}, \mathrm{SF} 7-20 \% \mathrm{CaCO}_{3]}\right.$

\begin{tabular}{|c|c|c|c|c|}
\hline \multirow{2}{*}{ Time (min) } & \multicolumn{4}{|c|}{ Cumulative \% drug release } \\
\cline { 2 - 5 } & \multicolumn{2}{|c|}{$0.1 \mathrm{~N} \mathrm{HCL}$} & \multicolumn{2}{c|}{$6.8 \mathrm{pH}$ phosphate buffer } \\
\cline { 2 - 5 } & $\begin{array}{c}\mathrm{SF} 6 \\
25 \% \mathrm{CaCo}_{3}\end{array}$ & $\begin{array}{c}\mathrm{SF} 7 \\
20 \% \mathrm{CaCo}_{3}\end{array}$ & $\begin{array}{c}\mathrm{SF} 7 \\
20 \% \mathrm{CaCo}_{3}\end{array}$ \\
\hline 0 & 0 & 0 & 0.00 & 0 \\
\hline 5 & 53.98 & 64 & 68.00 & 58.4 \\
\hline 10 & 76.25 & 71.7 & 92.30 & 95.1 \\
\hline
\end{tabular}




\begin{tabular}{|c|c|c|c|c|}
\hline & & & & \\
\hline 15 & 82.37 & 82.8 & 95.20 & - \\
\hline 20 & 84.67 & 86.9 & 100.70 & - \\
\hline 30 & 100.06 & 100.6 & - & - \\
\hline 45 & - & - & 0.9858 & 0.3801 \\
\hline $\mathrm{R}$ & 0.9589 & 0.9639 & 0.2755 & 1.8 \\
\hline $\mathrm{k}(\min -1)$ & 0.1491 & 0.1744 & 2.5 & 6.1 \\
\hline $\mathrm{T}_{50}$ (min) & 4.7 & 4 & 8.4 & \\
\hline $\mathrm{T}_{90}$ (min) & 15.4 & 13.2 & & \\
\hline
\end{tabular}

Nill - Without Alkalizing agents.\% - Quantity of Alkalizing agents present in the concerned formulation

Table 10:-Cumulative drug dissolution data of Sucralfate Tablets formulated with different concentrations of (Alkalizing agent : $\mathrm{CaCO}_{3}$ and $\mathrm{NaHCO}_{3}$ [ $\left.\mathrm{SF} 9,-20 \% \mathrm{NaHCO}_{3}, \mathrm{SF} 14-15 \% \mathrm{NaHCO}_{3} \mathrm{SF} 15-25 \% \mathrm{NaHCO}_{3}\right]$

\begin{tabular}{|c|c|c|c|c|c|c|}
\hline \multirow[t]{4}{*}{ Time (min) } & \multicolumn{6}{|c|}{ Cumulative $\%$ drug release } \\
\hline & \multicolumn{3}{|c|}{$0.1 \mathrm{~N} \mathrm{HCL}$} & \multicolumn{3}{|c|}{$6.8 \mathrm{pH}$ phosphate buffer } \\
\hline & SF9 & SF14 & SF15 & SF9 & SF14 & SF15 \\
\hline & $30 \%$ NaHсо 3. & $25 \% \mathrm{NaHco3}$ & $25 \% \quad \mathrm{NaHco} 3$ & $30 \% \mathrm{NaHco} 3$ & $25 \% \mathrm{NaHco} 3$ & $25 \% \mathrm{NaHco3}$ \\
\hline 0 & 0 & 0 & 0 & 0 & 0 & 0 \\
\hline 5 & 56.98 & 38.629 & 97.583 & 74.3 & 57.7 & 60.9 \\
\hline 10 & 81.83 & 69.34 & 89.838 & 99.4 & 74.1 & 101.1 \\
\hline 15 & 89.08 & 78.61 & 92.229 & 100.5 & 100.7 & - \\
\hline 20 & 94.03 & 84.494 & 100.826 & - & 101.9 & - \\
\hline 30 & 98.37 & 96.051 & - & - & - & - \\
\hline 45 & 101.41 & 98.683 & - & - & - & - \\
\hline $\mathrm{R}$ & 0.9965 & 0.997 & 0.9715 & 0.9482 & 0.9886 & 0.9999 \\
\hline $\mathrm{k}(\min -1)$ & 0.1954 & 0.0997 & 0.279 & 0.428 & 0.2935 & 0.6292 \\
\hline $\mathrm{T} 50$ & 4.3 & 7 & 2.5 & 1.6 & 2.4 & 1.1 \\
\hline T90 & 14.4 & 23.1 & 8.3 & 5.4 & 7.8 & 3.7 \\
\hline
\end{tabular}




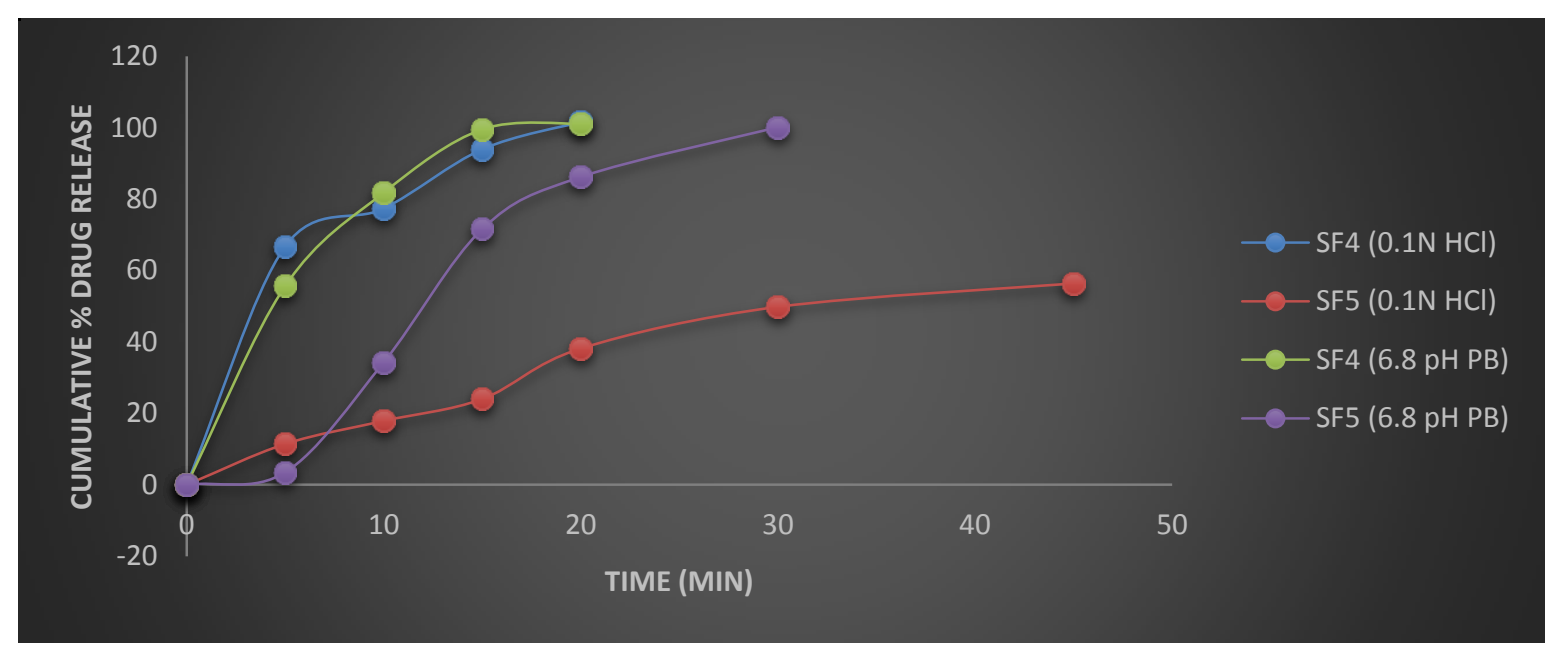

SF4: Without alkalizing agent; SF5: Alkalizing agent (30\%)

Fig 5:-In vitro drug dissolution profiles of sucralfate tablets formulated with and without (Alkalizing agen $\mathrm{CaCo}_{3}$ and $\mathrm{NaHCO}_{3}$ t at $0.1 \mathrm{~N} \mathrm{HCL}$ and $6.8 \mathrm{pH}$ respectively

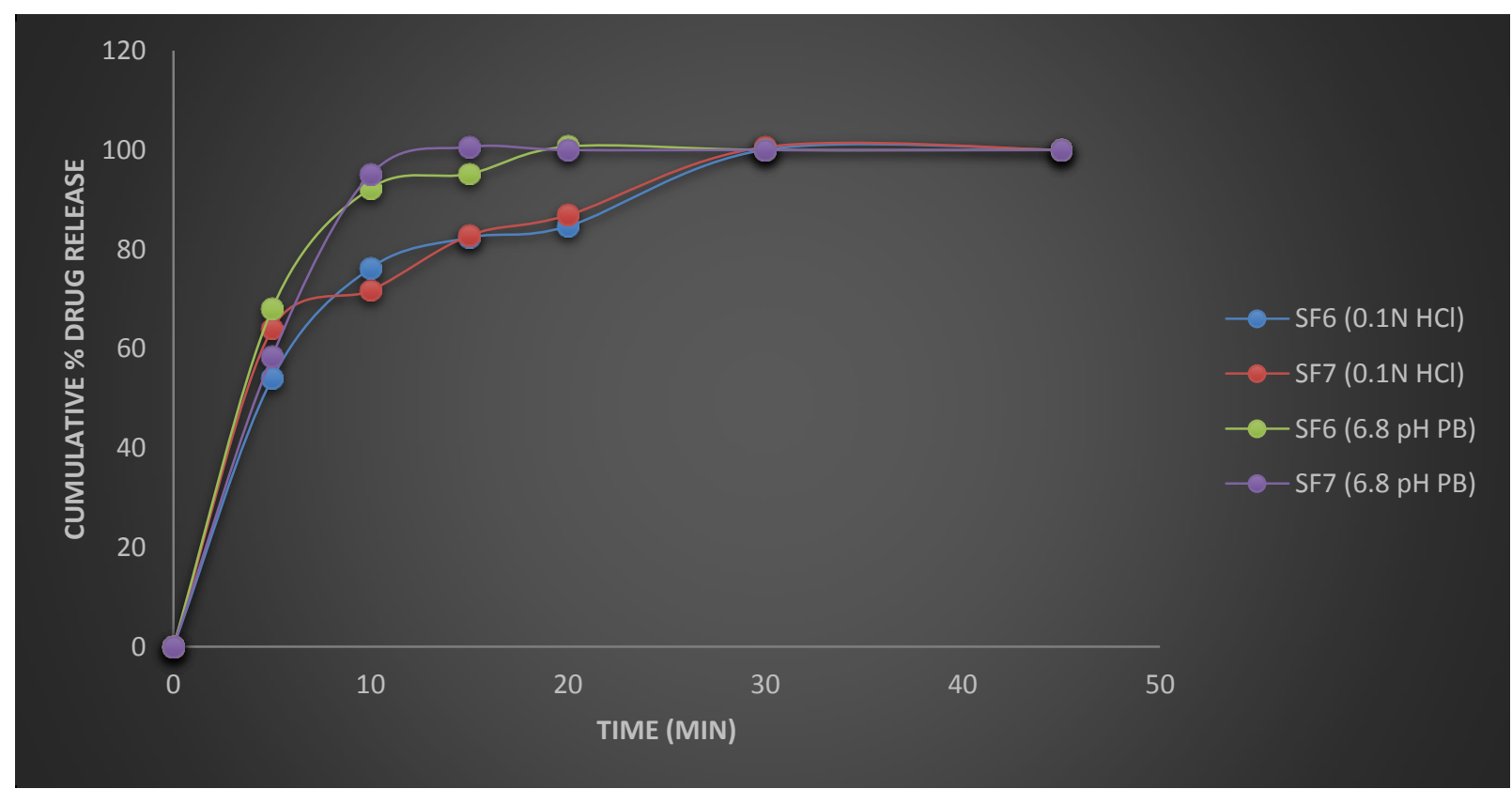

SF6: Calcium carbonate 25\% ; SF7: Sodium bicarbonate $20 \%$

Fig 6:-In vitro drug dissolution profiles of sucralfate tablets formulated with different (Alkalizing agents $\mathrm{CaCo}_{3}$ and $\mathrm{NaHCO}_{3}$ at $0.1 \mathrm{~N} \mathrm{HCL}$ and $6.8 \mathrm{pH}$ respectively. 


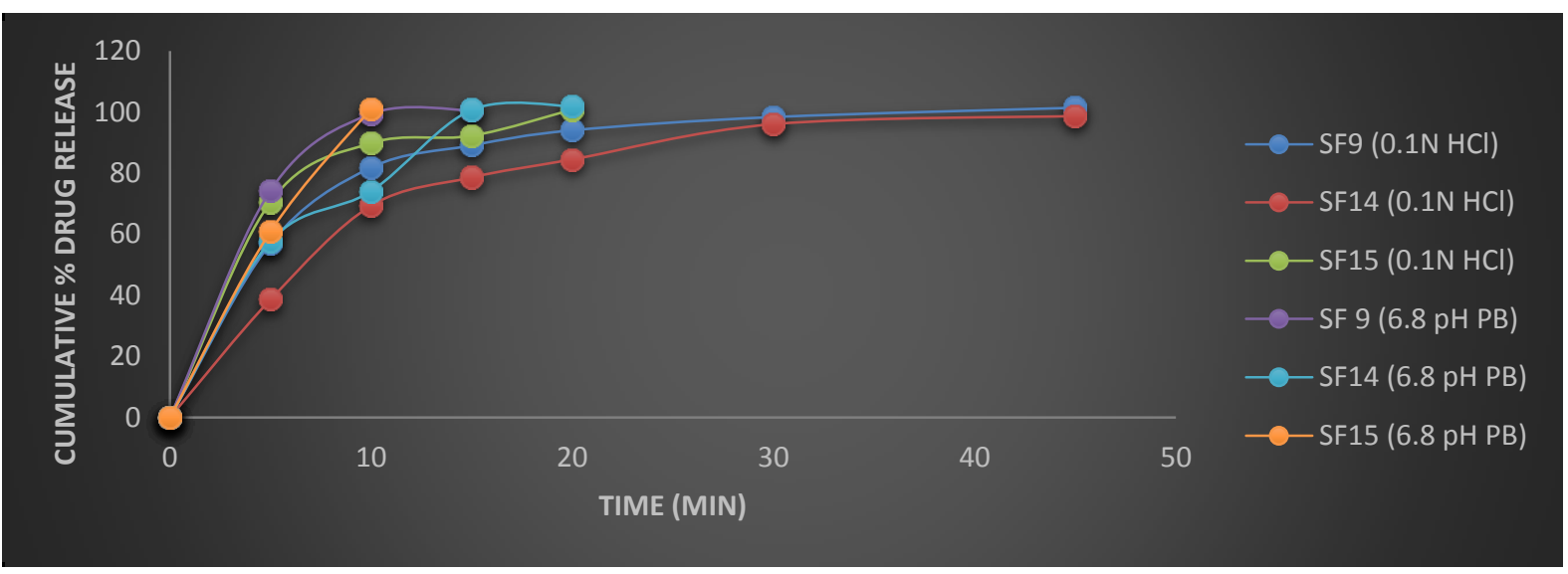

SF9: 20\% alkalizing agent; SF14: 15\% alkalizing agent; SF15: 25\% alkalizing agent

Fig 7:-In vitro drug dissolution profiles of Sucrafate tablets formulated with different concentrations of (Alkalizing agent $\mathrm{CaCo}_{3}$ and $\mathrm{NaHCO}_{3}$ at $0.1 \mathrm{~N} \mathrm{HCL}$ and $6.8 \mathrm{pH}$ respectively

2.2.5- Drug dissolution data with (Binding agents HPC) in presence of 0.1 HCL \& 6.8 Phosphate buffer of [SF8(Nill),,SF9(2\%), SF9--(3\%), SF10- (1\%), SF11 (5\%)]

Table 11:-Cumulative drug dissolution data of Sucralfate tablets formulated with and without (Binding agent:HPC) of [SF8-(Nill),,SF9(2\%), SF9--(3\%)]

\begin{tabular}{|c|c|c|c|c|}
\hline \multirow{2}{*}{ Time (min) } & \multicolumn{4}{|c|}{ Cumulative \% drug release } \\
\cline { 2 - 5 } & \multicolumn{3}{|c|}{$0.1 \mathrm{~N}$ HCL } & \multicolumn{2}{c|}{$6.8 \mathrm{pH}$ phosphate buffer } \\
\cline { 2 - 5 } & SF8(Nill) & SF9(2\%) & 0 & SF9(2\%) \\
\hline 0 & 0 & 0 & 55.5 & 0 \\
\hline 5 & 48.99 & 56.98 & 78.4 & 94.3 \\
\hline 10 & 75.18 & 81.83 & 93.5 & 100.5 \\
\hline 15 & 84.62 & 89.08 & 99.3 & - \\
\hline 20 & 88.41 & 94.03 & 100.1 & - \\
\hline 30 & 100.35 & 98.37 & - & 0.9482 \\
\hline 45 & - & 101.41 & 0.935 & 0.428 \\
\hline $\mathrm{R}$ & 0.9868 & 0.9965 & 0.2173 & 1.6 \\
\hline $\mathrm{k}$ (min-1) & 0.173 & 0.1954 & 3.2 & 5.4 \\
\hline T50 & 4 & 4.3 & 10.6 & - \\
\hline T90 & 13.3 & 14.4 & & \\
\hline
\end{tabular}

Table12:-Cumulative drug dissolution data of Sucralfate Tablets formulated with different concentrations of (Binding agents:HPC) [SF9--(3\%),SF10- (1\%), SF11 (5\%)]

Nill - Without Binding agents.

$\%$ - Quantity of Binding agents present in the concerned formulation.

\begin{tabular}{|c|c|c|c|c|c|c|}
\hline \multirow{2}{*}{ Time (min) } & \multicolumn{5}{|c|}{ Cumulative \% drug release } \\
\cline { 2 - 7 } & \multicolumn{5}{|c|}{$0.1 \mathrm{~N}$ HCL } & \multicolumn{3}{|c|}{ 6.8pH phosphate buffer } \\
\cline { 2 - 7 } & SF9(3\%) & SF10(1\%) & SF11(5\%) & SF9(3\%) & SF10(1\%) & SF11(5\%) \\
\hline 0 & 0 & 0 & 0 & 0 & 0 & 0 \\
\hline 5 & 56.98 & 95.53 & 53.74 & 74.3 & 69.4 & 65.4 \\
\hline 10 & 81.83 & 90.22 & 78.49 & & 100.2 & 83.6 \\
\hline 15 & 89.08 & 92.4 & 88.44 & & - & 84.2 \\
\hline
\end{tabular}




\begin{tabular}{|c|c|c|c|c|c|c|}
\hline & & & & 100.5 & - & 93.9 \\
\hline 20 & 94.03 & 98.62 & 89.3 & - & - & 100.7 \\
\hline 30 & 98.37 & 101.98 & 99.74 & - & - & - \\
\hline 45 & 101.41 & - & 100.68 & - & 0.999 & 0.9701 \\
\hline $\mathrm{R}$ & 0.9965 & 0.9829 & 0.9507 & 0.9482 & 0.1831 \\
\hline $\mathrm{k}(\mathrm{min}-1)$ & 0.1954 & 0.2155 & 0.1541 & 0.428 & 0.5773 & 1.2 \\
\hline T50 & 4.3 & 3.2 & 4.5 & 1.6 & 3.8 \\
\hline T90 & 14.4 & 10.7 & 14.9 & 5.4 & 4 & 12.6 \\
\hline
\end{tabular}

SF8: Without binder; SF9: With binder(2\%)

Fig 8:-In vitro drug dissolution profiles of sucralfate tablets formulated with and without (Binding agents :HPC) at $0.1 \mathrm{~N} \mathrm{HCL}$ and $6.8 \mathrm{pH}$ respectively.
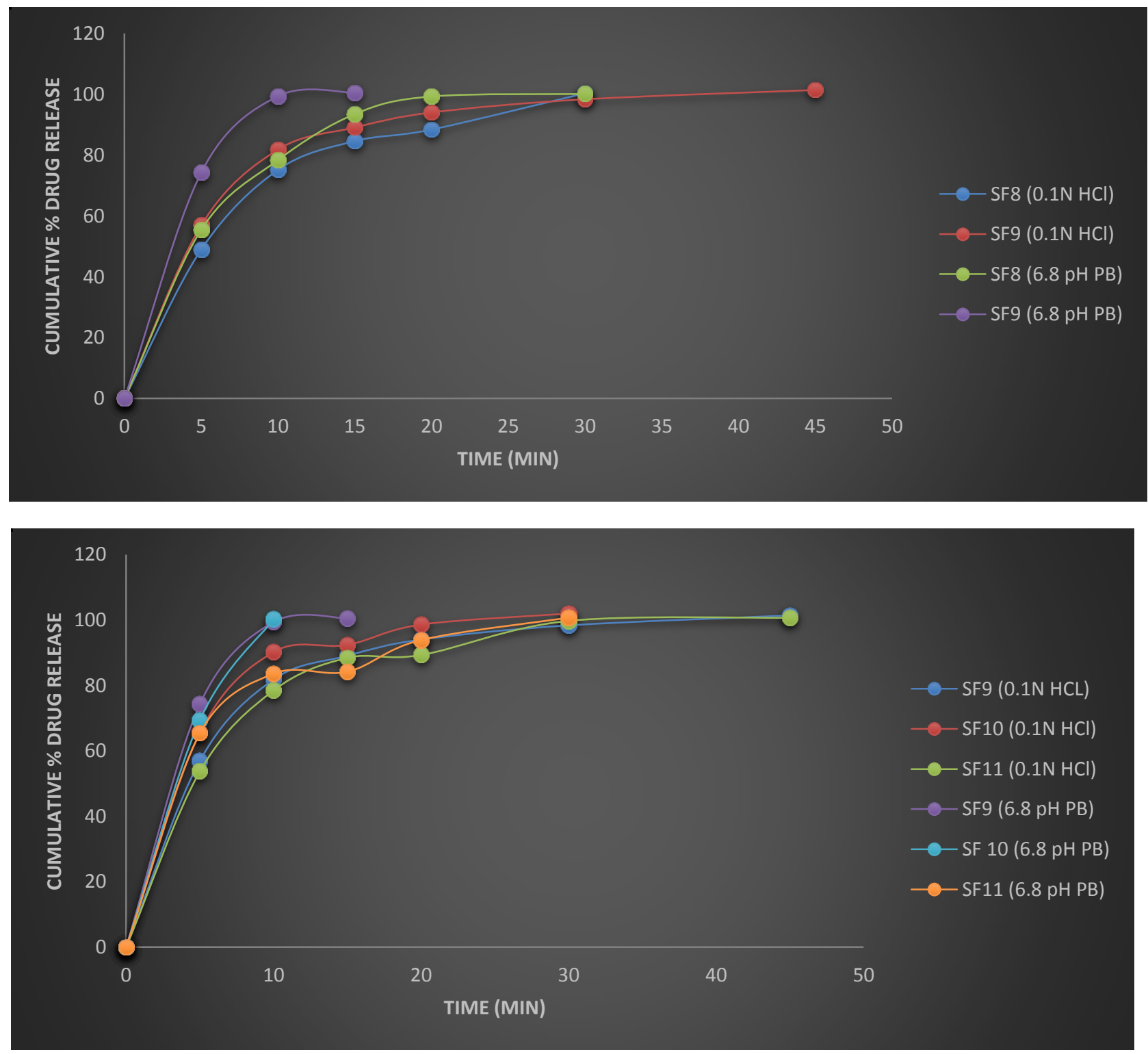

SF9: 3\% binder; SF10: 1\% binder; SF11: $5 \%$ binder

Fig 9:-In vitro drug dissolution profiles of sucralfate tablets formulated with different concentrations of (Binding agents:HPC) at $0.1 \mathrm{~N} \mathrm{HCL}$ and $6.8 \mathrm{pH}$ respectively. 


\section{Optimization of Metoprolol succinate formulation.}

In vitro drug release studies of Metoprolol Succinate tablets:

In vitro drug release studies were performed for all the formulated NA tablets. The method and equipment used for the study were previously validated. The tablets were placed in sinkers and were dropped into 6 bowls of dissolution apparatus (USP Type-II) . Previously degassed $900 \mathrm{ml}$ of $0.1 \mathrm{~N} \mathrm{HCl}$ was employed as dissolution media. The paddle speed was set at $100 \mathrm{rpm}$ and temperature was maintained at $37 \pm 0.5^{\circ} \mathrm{C}$. The sampling volume was $10 \mathrm{ml}$ and the same was replenished with fresh dissolution medium. The samples were collected at 1, 3, 6, 9, 12 and 20 hours. The samples were collected as pooled samples and were analyzed at $233 \mathrm{~nm}$ using UV-Spectrometer.

Cumulative \% drug release data were prepared of Metoprolol Succinate observed from formulations containing different concentrations of (Alkalizing agents;Sodium Bicarbonate). [MSF1(11\%),MSF2 (13\%)]

Table 13:-

\begin{tabular}{|c|c|c|}
\hline \multirow{2}{*}{ Time (hr) } & \multicolumn{2}{|c|}{ Cumulative \% drug release in 0.1 N HCl } \\
\cline { 2 - 3 } & MSF1(11\%) & MSF2(30\%) \\
\hline 0 & 0.00 & 0.00 \\
\hline 1 & & 17.08 \\
\hline 3 & 21.53 & 36.37 \\
\hline 6 & 38.99 & 54.65 \\
\hline 9 & 57.61 & 65.16 \\
\hline 12 & 71.67 & 77.39 \\
\hline 20 & 83.51 & 99.59 \\
\hline $\mathrm{R}$ & 97.94 & 0.9600 \\
\hline $\mathrm{k}(\mathrm{hr}-1)$ & 0.9844 & 0.1181 \\
\hline $\mathrm{T}_{50}(\mathrm{hr})$ & 0.1418 & 5.86 \\
\hline $\mathrm{T}_{90}(\mathrm{hr})$ & 4.88 & 19.49 \\
\hline Best fit model $_{\mathrm{n} \text { value }}$ & 16.23 & Higuchi \\
\hline
\end{tabular}

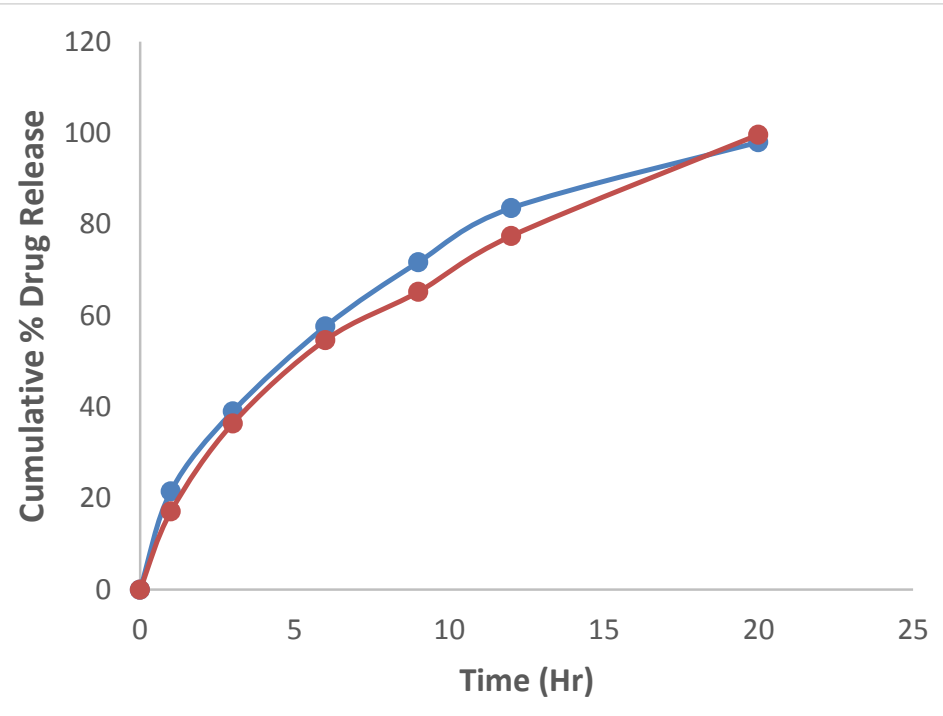

MSF1-(11\% Sodium Bicarbonate), MSF2-(13\% Sodium Bicarbonate),

Fig 10:-Drug release profiles of Metoprolol Succinate from tablets containing different concentrations of (Alkalizing agents;Sodium Bicarbonate). 
2.3.3.-Cumulative $\%$ drug release data prepared of Metoprolol Succinate from formulations containing different concentrations of ( HPMC K) [MSF2(33\%) ,MSF10 (23\%).]

Table 14:-

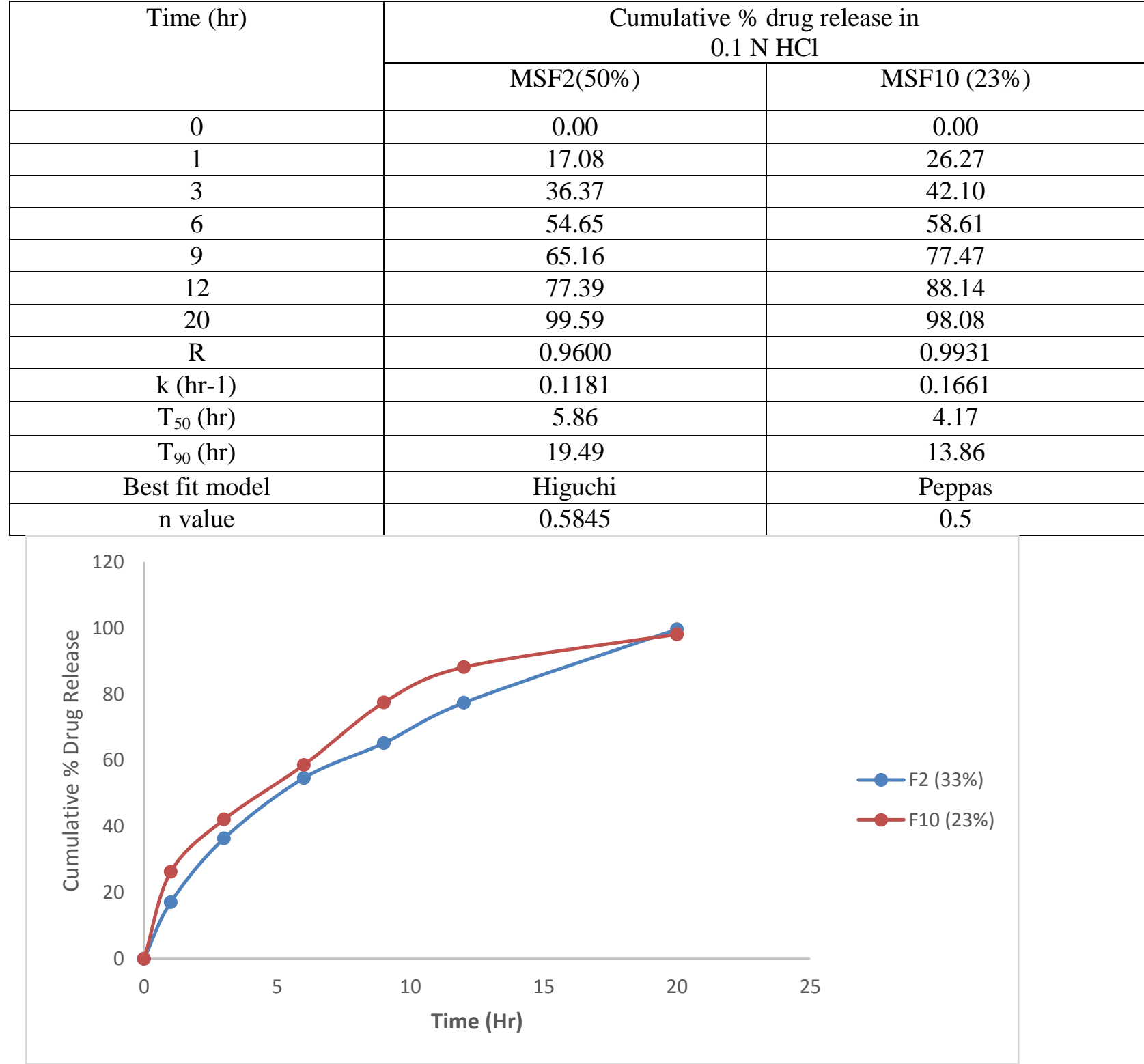

Fig 11:-Effect of HPMC concentration on cumulative drug release profile of Metoprol Succinate MSF2-(33\% HPMC), MSF10-(23\% HPMC)

Cumulative \% drug release data of Metoprolol Succinate observed from tablets formulated with different polymers. [MSF2(Eudragit RSPO-40\%),MSF3(Sodium CMC -35\%), MSF4(Sodium Alginate-30\%),MSF5 (HPC-25\%),MSF6 (EC-20\%),MSF7(Eudragit- LPO-15\%),MSF8 (Eudragit-RS100-10\%),MSF9(EC-10\%)]

Table 15:-

E-RSPO $=$ Eudragit - RSPO , E-LPO $=$ Eudragit LPO ,EC-Ethyl Cellulose
Time (hr)
Cumulative \% drug release in $0.1 \mathrm{~N} \mathrm{HCl}$ 


\begin{tabular}{|c|c|c|c|c|c|c|c|c|}
\hline & $\begin{array}{c}\text { MSF2 } \\
\text { E-RSPO } \\
40 \%\end{array}$ & $\begin{array}{c}\text { MSF3 } \\
\text { NaCMC } \\
35 \%\end{array}$ & $\begin{array}{c}\text { MSF4 } \\
\text { NaAlginate } \\
30 \%\end{array}$ & $\begin{array}{c}\text { MSF5 } \\
\text { HPC } \\
25 \%\end{array}$ & $\begin{array}{c}\text { MSF6 } \\
\text { EC } \\
20 \%\end{array}$ & $\begin{array}{c}\text { MSF7 } \\
\text { E-LPO } \\
15 \%\end{array}$ & $\begin{array}{l}\text { MSF8 } \\
\text { E-RS } \\
100 \\
10 \%\end{array}$ & $\begin{array}{c}\text { MSF9 } \\
\text { EC } \\
10 \%\end{array}$ \\
\hline 0 & 0.00 & 0.00 & 0.00 & 0.00 & 0.00 & 0.00 & 0.00 & 0.00 \\
\hline 1 & 17.08 & 24.03 & 21.39 & 22.04 & 22.09 & 23.31 & 20.84 & 20.36 \\
\hline 3 & 36.37 & 44.87 & 39.02 & 40.56 & 39.95 & 41.59 & 36.80 & 39.38 \\
\hline 6 & 54.65 & 69.07 & 57.65 & 58.66 & 61.18 & 60.06 & 53.61 & 59.98 \\
\hline 9 & 65.16 & 88.24 & 71.61 & 71.88 & 77.48 & 79.83 & 68.14 & 75.82 \\
\hline 12 & 77.39 & 96.45 & 82.18 & 83.11 & 91.32 & 88.81 & 86.65 & 81.97 \\
\hline 20 & 99.59 & 100.73 & 99.58 & 99.01 & 101.16 & 100.52 & 101.87 & 99.15 \\
\hline $\mathrm{R}$ & 0.9600 & 0.9910 & 0.94 & 0.9663 & 0.9892 & 0.99 & 0.9697 & 0.965 \\
\hline $\mathrm{k}(\mathrm{hr}-1)$ & 0.1181 & 0.2785 & 0.1349 & 0.139 & 0.1995 & 0.1749 & 0.1618 & 0.135 \\
\hline $\mathrm{T}_{50}(\mathrm{hr})$ & 5.86 & 2.48 & 5.13 & 4.98 & 3.47 & 3.96 & 4.28 & 5.13 \\
\hline $\mathrm{T}_{90}(\mathrm{hr})$ & 19.49 & 8.26 & 17.06 & 16.55 & 11.54 & 13.16 & 14.23 & 17.04 \\
\hline Best fit model & Higuchi & Peppas & Peppas & Peppas & Peppas & Peppas & Peppas & Higuchi \\
\hline $\mathrm{n}$ value & 0.5845 & 0.5103 & 0.5228 & 0.5098 & 0.5331 & 0.5094 & 0.5448 & 0.5400 \\
\hline
\end{tabular}

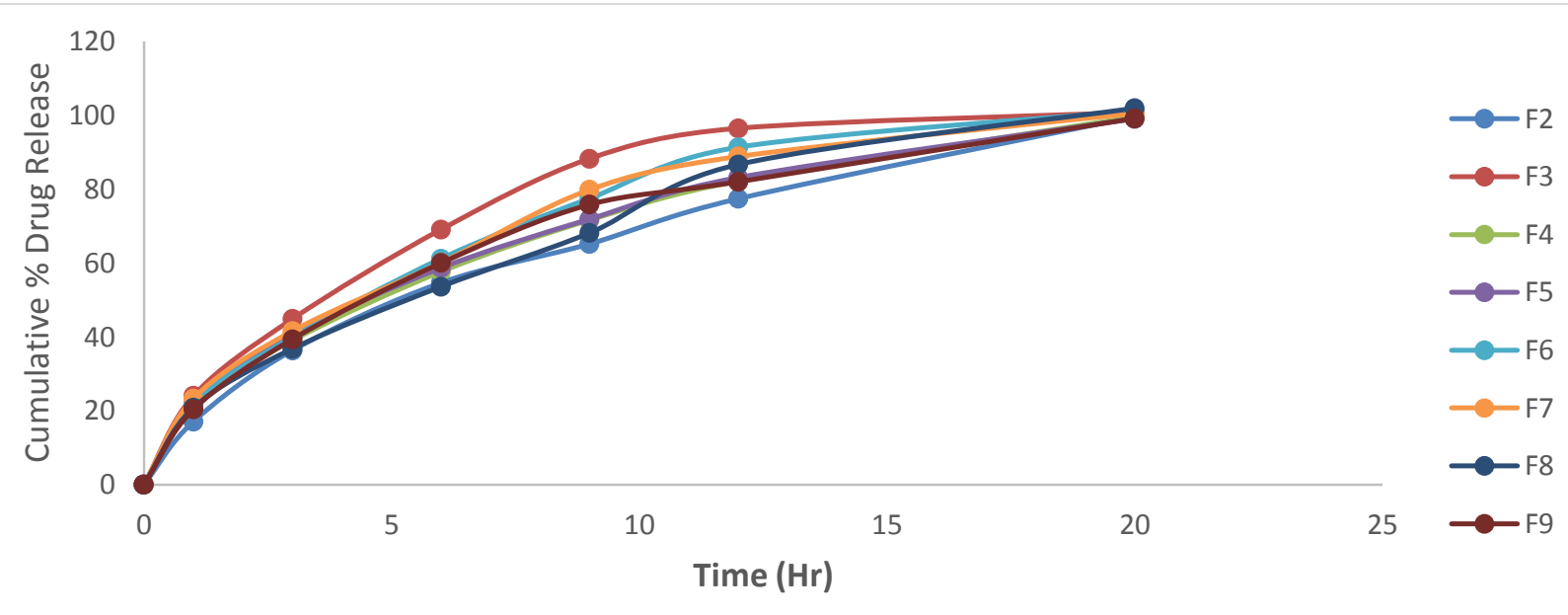

Fig12:-Cumulative \% drug release profiles of Metoprolol Succinate observed from formulations containing different polymers:[MSF2(EudragitRSPO-40\%),MSF3(SodiumCMC-35\%),MSF4(SodiumAlginate-30\%),MSF5 (HPC25\%),MSF6(EC-20\%),MSF7(Eudragit-LPO-15\%),MSF8(Eudragit-RS100-10\%),MSF9(EC-10\%)] 


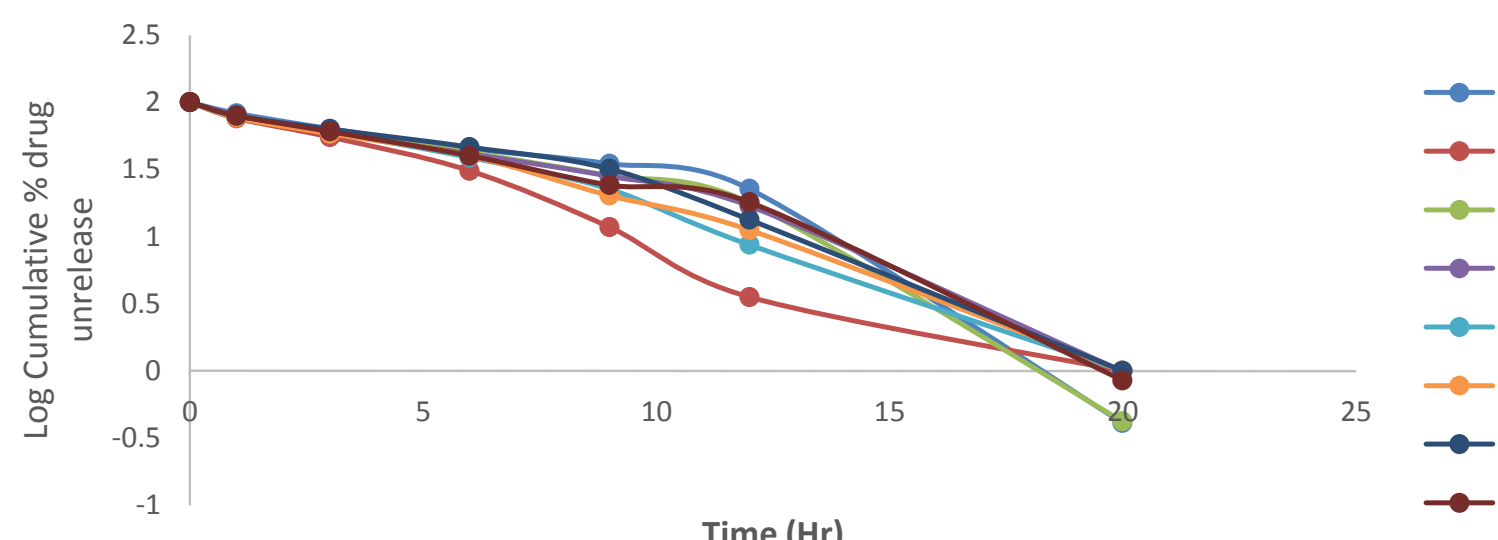

Fig13:-First order plots of Metoprolol Succinate from formulations containing different polymers: [MSF2(Eudragit RSPO-40\%),MSF3(Sodium CMC -35\%) ,MSF4(Sodium Alginate-30\%),MSF5 (HPC-25\%),MSF6 (EC20\%),MSF7(Eudragit- LPO-15\%),MSF8 (Eudragit-RS100-10\%),MSF9(EC-10\%)]

\section{4- Consideration of Optimized formulation: ${ }^{\text {Table-16,Table-17، Table-18 }}$}

Optimized formulations are developed by comparing the cumulative drug release of Sucralfate and Metoprolol Succinate at different time periods.

\section{RESULT AND DISCUSSION:-}

1. 3.1-Cummulative drug dissolution data of Sucralfate formulation.

2. 3.1.1- Cummulative drug dissolution data of Sucralfate formulation shows $71.42 \%$ release at 5 th minute inacid medium $(0.1 \mathrm{HCL})$ in presence of $7 \%$ (Crosspovidone as Superdisintigrant). Table-4,Table-5,Fig-1,Fig-2 .

3. 3.1.2-Cummulative drug dissolution data of Sucralfate formulation shows $66.74 \%$ release at 5 th minute in acid medium ( $0.1 \mathrm{HCL}$ ) in presence of 7\% (Polysorbate-80 as Surfectant) Table-6,Table7,Fig-3,Fig-4

4. 3.1.3-Cummulative drug dissolution data of Sucralfate formulation shows $70.583 \%$ release at 5 th minute in acid medium $(0.1 \mathrm{HCL})$ in presence of $15 \%$ Sodium Bicarbonate as Alkalizing agent. . Table-8,Table-9,Table-10, Fig-5,Fig-6,Fig-7 .

5. 3.1.4- Cummulative drug dissolution data of Sucralfate formulation shows $65.53 \%$ release at 5 th minute in acid medium(0.1 HCL) in presence of 5\% Hydroxy Propyl Cellulose as binding agent. . Table-11, Table-12, Fig8,Fig-9.

6. 3.2-Cummulative drug dissolution data of Metoprol Succinate formulation.

7. 3.2.1-Cummulative drug dissolution data of Metoprol Succinate formulation shows $99.59 \%$ release at 20th minute in acid medium (0.1 HCL) in presence of $30 \%$ of Sodium Bicarbonate as Alkalizing agent. Table-13, Fig-10

8. 3.2.2-Cummulative drug dissolution data of Metoprol Succinate formulation shows $99.46 \%$ release at 20th minute in acid medium $(0.1 \mathrm{HCL})$ in presence of $50 \%$ of HPMC as soluble polymer. Table-14,Fig-11

9. 3.2.3-Cummulative drug dissolution data of Metoprol Succinate formulation shows release at 20th minute in acid medium $(0.1 \mathrm{HCL})$ in presence of different polymers ; $99.39 \%$ at $40 \%$ of Udragit- RSPO, $100.73 \%$ at $35 \%$ of CMC, $99.58 \%$ at $30 \%$ of Sodium alginate, $99.01 \%$ at $25 \%$ HPC, $101.16 \%$ at $20 \%$ Ethyl Cellulose , $100.52 \%$ at $15 \%$ Udragit RLPO ,101.87\% at 10\% Eudragit RS ,99.15\% at 5\% Ethyl Cellulose. Table-15,Fig13

10. 3.3-Result of optimization of Sucralfate layer. Table-16

11. Within 5 minutes in $0.1 \mathrm{HCL}$ medium, $7 \%$ Superdisintigant (Crosspovidone) produce $71.42 \%$ drug release in SF13, 7\% Surfectant (Polysorbate-80) produce $66.74 \%$ drug release in SF4 ,15\% Alkalizing agents(Sodium bicarbonate) produce $70.583 \%$ drug release in SF15, 5\% HPC (Binding agent) produce $65.53 \%$ drug release in SF10.

Table 16:-Result of optimization of Sucralfate layer.

\begin{tabular}{|c|c|c|c|c|c|c|}
\hline $\begin{array}{r}\text { S1 } \\
\text { NO }\end{array}$ & INGREDIENTS & MEDIUM & $\begin{array}{r}\% \mathrm{OF} \\
\text { INGRADIENTS } \\
\text { TAKEN }\end{array}$ & $\begin{array}{r}\text { TIME IN } \\
\text { MINUTES }\end{array}$ & $\begin{array}{r}\% \text { OF } \\
\text { DRUG } \\
\text { RELEASE }\end{array}$ & FORMULATION \\
\hline
\end{tabular}




\begin{tabular}{|l|l|l|c|c|l|l|}
\hline 1 & $\begin{array}{l}\text { Superdisintigant } \\
\text { (Crosspovidone) }\end{array}$ & $0.1 \mathrm{HCL}$ & $7 \%$ & $5^{\text {th }}$ & $71.42 \%$ & SF13 \\
\hline 2 & $\begin{array}{l}\text { Surfectant } \\
\text { (Polysorbate-80) }\end{array}$ & $0.1 \mathrm{HCL}$ & $7 \%$ & $5^{\text {th }}$ & $66.74 \%$ & SF4 \\
\hline 3 & $\begin{array}{l}\text { Alkalizing } \\
\text { agents(Sodium } \\
\text { bicarbonate) }\end{array}$ & $0.1 \mathrm{HCL}$ & $15 \%$ & $5^{\text {th }}$ & $70.583 \%$ & SF15 \\
\hline 4 & $\begin{array}{l}\text { HPC (Binding } \\
\text { agent) }\end{array}$ & $0.1 \mathrm{HCL}$ & $5 \%$ & $5^{\text {th }}$ & $65.53 \%$ & SF10 \\
\hline
\end{tabular}

3.4-Result of optimization of Metoprol Succinate layer. ${ }^{\text {Table-17 }}$

Within 20 minutes in 0.1 HCL medium, 30\% Alkalizing agents(Sodium bicarbonate) produce $99.59 \%$ drug release in MSF2, 50\% Soluablepolymer (HPMC K) produce $99.46 \%$ drug release in MSF2 ,40\% Polymer (Udragid RSPO produce $99.59 \%$ drug release in MSF2, 35\% HPC Polymer(NaCMC) produce $100.73 \%$ drug release in MSF3,30\% Polymer (Sodiumalginate) produce 99.58\% drug release in MSF4, 25\% Polymer (HPC) produce $99.01 \%$ drug release in MSF5 , 20\% Polymer (Udragid RS) produce 101.87\% drug release in MSF8, 5\% HPC Polymer (PVPK) produce $99.15 \%$ drug release in MSF9.

Table-17:-Result of optimization of Metoprolol Succinate layer.

\begin{tabular}{|c|c|c|c|c|c|c|}
\hline $\begin{array}{r}\mathrm{Sl} \\
\mathrm{NO}\end{array}$ & INGRADIENTS & MEDIUM & $\begin{array}{r}\% \mathrm{OF} \\
\text { INGRADIENTS } \\
\text { TAKEN }\end{array}$ & $\begin{array}{r}\text { TIME IN } \\
\text { MINUTES }\end{array}$ & $\begin{array}{r}\% \text { OF } \\
\text { DRUG } \\
\text { RELEASE }\end{array}$ & FORMULATION \\
\hline 1 & $\begin{array}{l}\text { Alkalizing agent } \\
\text { (Sodium bicarbonate) }\end{array}$ & $0.1 \mathrm{HCL}$ & $30 \%$ & $20^{\text {th }}$ & $99.59 \%$ & MSF2 \\
\hline 2 & $\begin{array}{l}\text { Soluablepolymer } \\
\text { (HPMC K) }\end{array}$ & $0.1 \mathrm{HCL}$ & $50 \%$ & $20^{\text {th }}$ & $99.46 \%$ & MSF2 \\
\hline 3 & $\begin{array}{l}\text { Polymer } \\
\text { (Udragid RSPO) }\end{array}$ & $0.1 \mathrm{HCL}$ & $40 \%$ & $20^{\text {th }}$ & $99.59 \%$ & MSF2 \\
\hline 4 & Polymer(NaCMC) & $0.1 \mathrm{HCL}$ & $35 \%$ & $20^{\text {th }}$ & $100.73 \%$ & MSF3 \\
\hline 5 & $\begin{array}{l}\text { Polymer } \\
\text { (Sodiumalginate) }\end{array}$ & $0.1 \mathrm{HCL}$ & $30 \%$ & 20th & $99.58 \%$ & MSF4 \\
\hline 6 & Polymer(HPC) & $0.1 \mathrm{HCL}$ & $25 \%$ & 20th & $99.01 \%$ & MSF5 \\
\hline 7 & Polymer (EC) & $0.1 \mathrm{HCL}$ & $20 \%$ & 20th & $101.16 \%$ & MSF6 \\
\hline 8 & Polymer (Udragid RLPO) & $0.1 \mathrm{HCL}$ & $15 \%$ & 20th & $100.52 \%$ & MSF7 \\
\hline 9 & $\begin{array}{l}\text { Polymer } \\
\text { (Udragid-RS) }\end{array}$ & $0.1 \mathrm{HCL}$ & $10 \%$ & 20th & $101.87 \%$ & MSF8 \\
\hline 10 & Polymer(PVPK) & $0.1 \mathrm{HCL}$ & $5 \%$ & 20th & $99.15 \%$ & MSF9 \\
\hline
\end{tabular}

3.5-Composition of formulation of Optimized Sucralfate and Metoprolol Succinate (OSFMS) Bi Layered Floating Tablet. 
Table 18:-

\begin{tabular}{|c|c|c|c|c|}
\hline SL No & INGREDIENTS & $\begin{array}{c}\text { Quantity per } \\
\text { Ingredients in mg } \\
\text { OSF (Optimized } \\
\text { Sucralfate Layer) }\end{array}$ & INGREDIENTS & $\begin{array}{c}\text { Quantity per } \\
\text { Ingredients in mg } \\
\text { OMSF } \\
\text { (Optimized } \\
\text { Metoprolol } \\
\text { Succinate Layer) }\end{array}$ \\
\hline 1 & SUCRALFATE & 100 & $\begin{array}{l}\text { METOPROLOL } \\
\text { SUCCINATE }\end{array}$ & 50 \\
\hline 2 & CROSS POVIDONE & 7 & HPMC K 100 M & 25 \\
\hline 3 & AEROSIL & 1 & $\begin{array}{l}\text { SODIUM } \\
\text { BICARBONATE }\end{array}$ & 15 \\
\hline 4 & LACTOSEMFL & 31.25 & AEROSIL & 3 \\
\hline 5 & MCC PH101 & 43.575 & $\begin{array}{l}\text { EUDRAGIT- } \\
\text { RSPO }\end{array}$ & 20 \\
\hline 6 & SODIUM BICARBONATE & 15 & $\begin{array}{l}\text { EUDRAGIT- } \\
\text { RLPO }\end{array}$ & 7.5 \\
\hline 7 & POLYSORBATE 80 & 7 & $\begin{array}{l}\text { EUDRAGIT- } \\
\text { RS100 }\end{array}$ & 5 \\
\hline 8 & HPC-L & 5 & $\mathrm{Na} \mathrm{CMC}$ & 17.5 \\
\hline 9 & MAGNESIUM STEARATE & 3.75 & $\begin{array}{l}\text { SODIUM } \\
\text { ALGINATE }\end{array}$ & 15 \\
\hline 10 & SUNSET YELLOW $(0.25 \%)$ & 0.3125 & HPC & 12.5 \\
\hline 11 & PURIFIED WATER & qs & $\begin{array}{l}\text { ETHYL } \\
\text { CELLULOSE }\end{array}$ & 10 \\
\hline & TOTAL WEIGHT & 214 & PVPK -90 & 2.5 \\
\hline 12 & & & TALC & 3 \\
\hline 13 & & & IPA & Q.S \\
\hline 14 & & & $\begin{array}{l}\text { PURIFIED } \\
\text { WATER }\end{array}$ & Q.S \\
\hline 15 & & & TOTAL WEIGHT & 186 \\
\hline
\end{tabular}

\section{Conclusion:-}

The optimized formulation $400 \mathrm{mg}$ tablet weight of OSFMS (Optimized Sucralfate and Metoprolol Succinate Formulation) Sucralfate in acidic medium produce averagely $68.56 \%$ drug release within 5 minutes. Within 20 hours Metoprolol Succinate produce averagely $100.06 \%$ drug release release in acidic medium and identified as better formulation for further studies.

\section{Future aspects:}

The development and optimization of Bi-Layered Floating Tablet of Sucralfate and Metoprol Succinate produce a new era to formulate a new formulation producing better release at low tablet weight can full fill the proper therapeutic effect of the drugs and it generate a new scope for future generations.

\section{Acknowledgement:-}

I would like to express my special thanks of gratitude to my Guide Dr Bibhuti Bhusan Panigrahi and Co Guide Dr Monoj Kumar Pani as well as The Principal who gave me a golden opportunity to proceed on my research work on the topic which helped in enhancement of my knowledge and ability.I am really thankful to them. 
Secondly i would like to thank my parents, my family and supporting staffs who helped me a lot in fulfilment of the work.Finally i would like to thank to God for blessing of further proceed.

\section{Conflict of intrest:}

The authors declare that there no conflict of interest regarding the study.

\section{References:-}

1. MuheemA.Optimizationtechniques.in.pharmaceutics.formulation-processing.2007; Avilable athtpps//www.slideshare.net/mobile/MUHEEM-007/optimization-in

2. Pathekar S, Suggala V, Ghopeap S ,Salunka R, Jain H, Swain K. Review on Bi-layer Floating Tablets .WJPPS $2016 ; 2: 1411-13$.

3. Arora S, Ali J , Ahuja A, Khar R.K, Mabota S. Floating Drug Delivery System ; A review. AAPS Pharma Science tech $2005 ; 3$ : E 372-89.

4. Verma R, Kishor D, Tushar G. Bi- Layer Tablet for Various Drugs : A review. SAJP 2014 ; 3: 271-79.

5. Biswal B .Design development and evaluation of Trimetazidine Di hydrochloride Floating Bi-Layer M.R Tablet IRJP 2011 ; 7: 92-97.

6. Garg R K ,Singhvi I. Bilayer Floating Tablet Technology : An Overview ; IJPPR 2015, 3: 302-22.

7. Kardumpala S, Chetty M, Gnanaprakash K, Venkatesh B, Sankar P. A review on Bilayer Floating Tablets. IJRPS 2013; 2:354-60.

8. Regardh CG, Lundborg P, Persson BA, The effect of antacid, metoclopramide, and propantheline on the bioavilability of metoprolol and atenolol Biopharm Drug Dispos.1981; 2 :79-87

9. Drug interaction between Metoprolol succinate ER and sucralfate. Avilable at- https:// www.drugs.com / drug interaction / metoprol Succinate ER with .sucralfate - $1615-14142-2118$ o.html ?professional $=1$

10. Wakade Ravikiran B.Devlopment and Optimization of Bilayer Floating Tablets of Glipizide .RJPS 2013; (9):8-12.

11. Rajendra K, Krishna M C, A Compresive Review On Gastroretaintive Drug Delivery System. AJPS 2016; 3 (2): 115-128 .

12. Das SR, Panigrahi BB, Pani MK. Formulation and Evaluation of Sucralfate and Metoprol succinate Bi-Layer Floating Tablet as Gastro Retaintive Drug Delivery. 